\title{
Using Electronic Communication Tools in Online Group Activities to Develop Collaborative Learning Skills
}

\author{
Hanan Khalil ${ }^{1, *}$, Martin Ebner ${ }^{2}$ \\ ${ }^{1}$ Department of Instructional Technology, Faculty of Education, Mansoura University, Egypt \\ ${ }^{2}$ Information Technology Services, Department of Social Learning, Graz University of Technology, Austria
}

Copyright $\bigcirc 2017$ by authors, all rights reserved. Authors agree that this article remains permanently open access under the terms of the Creative Commons Attribution License 4.0 International License

\begin{abstract}
The purpose of this study was to investigate the effect of using synchronous and asynchronous communication tools in online group activities to develop collaborative learning skills. An experimental study was implemented on a sample of faculty of education students in Mansoura University. The sample was divided into two groups, a group studied using synchronous communication tools, and the other group studied using asynchronous communication tools. The findings highlighted the fact that electronic communication tools have an effect to develop collaborative skills. However, the researchers found that the synchronous communication tools are more useful than asynchronous communication tools for developing collaborative learning skills in online group activities. The implications of the findings offer support for using synchronous communication tools in online group activities to develop collaborative skills.
\end{abstract}

Keywords Electronic Communication Tools, Online Group Activities, Collaborative Learning

\section{Introduction}

Though each student is assessed individually, group activities in the classroom support the success of the individual as well as the group. More often students' success relies on collaborative learning when sharing ideas in online discussions and simulations [1]. From an online class perspective designing methods for social interaction and collaboration provides their basic foundation. The key to a successful online class is to evaluate and to select the types of communication tools that fit the instructor's pedagogy, the needs of the learner, and the objectives of the course. Electronic tools have the potential to be used for communication purposes and to provide instructional resources in educational environments [2], [3]. It is claimed that the access and use of these tools is a useful practice for the development of higher order thinking skills, learner centered pedagogy, active and authentic learning, associative thinking, and for supporting online learning communities [4], Farmer, [2], Electronic communication tools have considerable promise for supporting collaborative learning. When designing course activities, categorizing electronic communication tools in separate categories by asynchronous (e.g. anytime communication) and synchronous (e.g. live communication) will help to identify the composition of the activity. Asynchronous communication and collaboration tools include e.g. E-mails, discussion forums, Wikis, Blogs, or Google Docs, while synchronous tools include e.g. chats, videoconferencing or Etherpad [5], [6]. These tools are relatively easy to use and help build a sense of community in the online classroom. Porter (2004) indicated that both types of communication tools are providing group learners with different preferences, and allow the flexibility of matching the students preferred learning style.

Wang [7] pointed out that using synchronous communication tools in online group activities offer real-time collaboration, immediate response and feedback, many low-cost and free solutions, useful for 1 to 1 communication, and allow limited body language and tone of voice. In contrast Ellis, \& Romano. [8] suggested the effectiveness of asynchronous communication tools as they are available anytime and anyplace can be incorporated by a variety of different information systems, document the whole collaboration process and can be used for one to one communication as well as one to many communication. However, there is a lack on studies who suggested which type of communication tools is effective in online group activities to develop collaborative skills. Therefore our research work will exactly point to this issue. As a consequence an experimental study on the faculty of education was implemented to investigate the effect of using synchronous, and asynchronous collaboration tools in online group activities to develop collaborative learning skills.

\subsection{Theoretical Background}

Distance learning is a pedagogy implemented remotely and therefore benefits students who may not be able to study 
in the traditional way [9]. It offers learners the opportunity to study flexibly and it provides an opportunity to enroll on courses not available in their country [10]. Distance learning can be a lonely experience for students who may feel isolated and unsupported. However it is possible to use technology to motivate students to interact with each other and their tutors and work together towards common goals. It provides distance learners specifically with a sense of learning collaboratively within a community rather than on their own and therefore enables them to learn more effectively [11].

\subsection{Collaborative Learning}

Collaborative learning is defined as a pedagogy in which people come together in groups and learn from each other through cooperation [10]. Each student takes responsibility for the learning of other students in their group as well as their own and they help each other to be successful [12]. In collaborative learning, two or more learners are working together in a learning environment. Anuratha [13] has defined collaborative learning as the interdependence of the individuals as they share ideas and reach a conclusion or product. Collaboration among learners is seen as an important crux to learning where participants interact with each other and exchange ideas and share information with each other. Collaborative learning views knowledge as a social construct that stimulates active social interaction that could stimulate learning as learners work together independently and bring together their results into the final output.

Generally, learners will perform activities like asking questions, providing explanation and navigating the interaction that triggers learning. This will eventually generate both cognitive learning outcomes and social competency. Finally, collaborative learning found its way in the virtual world and created a new field in educational scenario that merges the notion of group-based learning and the potential of communication technology. Collaborative learning correlates to positive affective outcomes (e.g. [14], [15] such as higher motivation, higher self-esteem, more favorable attitude towards learning, and increased persistence. To be collaborative, learning groups must be carefully structured to include the five basic elements identified by Johnson, Johnson, \& Smith [16]: (1) positive interdependence to ensure that students believe they "sink or swim together," (2) promotive interaction to ensure that students help and assist each other, (3) individual accountability to ensure that everyone does their fair share of the work, (4) social skills to work effectively with others, and (5) group processing to reflect on and improve the quality of group work.

Studies confirm that learners need to be trained to work collaboratively for their future careers [17], [18], In addition, collaboration is the key to a successful online learning is to develop a strong sense of community and collaboration among learners. collaboration is linked to learners' greater satisfaction with their academic program and to reduced feelings of isolation [19]. Mattehewsf \& part (2003) reported that promote collaborative learning in distance programs, you will want to structure online group activities to encourage the kind of student interactions and active learning that foster deep learning. Online group activities should be planned and executed much like face-to-face activities - probably even more so for the asynchronous online classroom.

\subsection{Online Group Activities}

Group activities provide several important benefits in online teaching and learning environment as follows: [20].

- Help participants discuss concepts that promote deeper understanding of the material.

- Engage participants in the learning process and increase participation.

- Allow participants to tackle more complex problems.

- Give each participant experience in handling interpersonal processional relations, which is critical in "real- world" settings.

- Provide or improve practice evaluation skills as working professionals.

- Help create a sense of learning community, which is important for online students.

- Allow group members to assess other members of the team as well as self- evaluation.

- Assist participants to develop skills in independent judgments and encourage sense of involvement and responsibility on the part of students.

- Provide data that might be used in assigning individuals grades for team assignments.

- Improve learning and produce higher quality results.

- Reduce instructors workload involved in assessing and grading.

\subsection{Electronic Communication Tools}

Electronic communication tools pervade our life and change our way of working with the Internet [21]. According to ([22], [23], [24], [25], web 2.0 tools have the potential to be used as a communication means, and instructional resources in educational environments [2], [3]. It is claimed that the access and use of these tools is a useful practice for the development of higher order thinking skills, learner centered pedagogy, active and authentic learning, associative thinking, and interactive learning communities [3], [2]. With electronic communication tools, there are some things changing. Users are creating their content and learn in other forms than traditional planned courses [26]. Moreover, communication tools have considerable promise for supporting collaborative learning.

\section{Synchronous and Asynchronous Communication Tools}

Asynchronous communication takes place outside of real time. For example, a learner sends you an e-mail 
message. You later read and respond to the message. There is a time lag between the time the learner sent the message and you replied, even if the lag time is short Asynchronous communication take place whenever learners have the time to complete them. For example, viewing videos linked to the course site, reading a textbook, and writing a paper are all asynchronous activities .In contrast, synchronous, or real-time, communication takes place like a conversation. If your class uses only writing-based tools to communicate, the only synchronous communication possible is a chat session. Everyone gets online in the same chat room and types questions, comments, and responses in real time. Synchronous activities may include chat sessions, whiteboard drawings, and other group interactive work.

Ellis \& Romano [8] suggested that Synchronous tools enable real-time communication and collaboration in a "same time-different place" mode. They reported that these tools allow people to connect at a single point in time, at the same time. Schwier \& Balbar [27] pointed out that Synchronous tools possess the advantage of being able to engage people instantly and at the same point in time on the other hand Ellis \& Romano [8] suggested that Asynchronous tools enable communication and collaboration over a period of time through a "different time-different place" mode. These tools allow people to connect together at each person's own convenience and own schedule.

Asynchronous communication and collaboration tools include e.g. E-mails, discussion forums, Wikis, Blogs, or Google Docs, these tools offer the opportunity for a single conversation to occur over days, weeks or even an entire term. Whereas, synchronous tools include e.g. chats, videoconferencing or Etherpad .These tools have become inexpensive to the point of nearly free to those with access to the required hardware (computer or mobile device with speakers, microphone and an optional video camera. Internet telephone offerings, such as Skype and Google Voice, offer free calls between accounts. Both also offer chat features that allow attendees without the required microphone to have a (written) voice in the conversation.

Both types of communication have their disadvantages, however. Disadvantages of synchronous communication include: getting students online at the same time, difficulty in moderating large-scale conversations, lack of reflection time for students, and intimidation of poor typists. Educators also cited the limitations of asynchronous communication: lack of immediate feedback, students not checking in of- ten enough, length of time necessary for discussion to mature, and students feeling a sense of social disconnection. On the other hand, disadvantages of asynchronous communication include: No real time discussions, live collaboration, Immediate feedback, or real time activities to increase motivation \& engagement.

However, there is a lack on studies who suggested which type of communication tools is effective in online group activities to develop collaborative skills. Therefore our research will focus on this point .As a consequence an experimental study on the faculty of education students in Mansoura University was implemented to address the following question:

What is the difference between the effect of using synchronous and asynchronous communication tools in online group activities to develop collaborative learning skills?

\section{Research Methodology}

In this section description for the research design, the participants of the study, learning environment and data collection and analysis is provided.

\subsection{Research Design}

As DiPetta [28] mentioned, "Experiences in virtual environments are like snowflakes-no two are alike" (p. 62). In this regard, the research purpose is to describe the effect of using synchronous and asynchronous communication tools in online group activities to develop collaborative skills. Thus, the design of two experimental groups was used, a group used synchronous communication tool, and another group used asynchronous communication tool

\subsection{Participants}

Participants belonged to one of two groups of learners. The learners had enrolled in a instructional design course available on Moodle in an instructional-technology professional diploma at Mansoura University in Egypt. Students were selected according to the purposive-sampling method. Group 1 consisted of 18 learners who were using synchronous communication tool (video call) in their online group activities of the course, and Group 2 consisted of 16 learners who were using asynchronous communication tool (wiki) in their online group activities of the course. Most of the learners had acquired little or no multimedia authoring knowledge before taking this class.

\subsection{Learning Environment}

In this study, synchronous communication tool (Skype) functioned as a supplemental tool for the first experimental group, it was the only tool that enables real-time and two-way oral and video communication among multiple participants. Participants in the chat room could communicate via text and oral conversation. Ten participants were already using skype so We instructed the rest of the participants to register a skype account for messenger installation. We did not adopt the chat tool that is available in MOOdle because it does not offer oral or video communication function. The group chat sessions constituted a forum where learners could discuss online group activities, and could respond to one another's 
questions. The other group Supplemented with as asynchronous communication tool (wiki), it was the only tool available for participants to discuss their online group activities, and communicated with each other. We instructed all participants of the second group to register a Wikipedia account because none of them has an account there. Each group of learners received the same instruction as did the other group. The only difference was that one group participated in only group activities using synchronous tool (skype) and the other online group participated in online group activities using asynchronous communication tool (wiki) . In both groups, every learner was assigned to participate in online group activities so that the pair could develop collaborative learning skills . As the present study reflects our effort to develop collaborative learning skills. A checklist of collaborative learning skills was designed for this purpose (appendix 1). It consists of 44 items the checklist was applied on the learners of the two groups after and before using the communication tools (synchronous and asynchronous). we expected that the two groups of learners would demonstrate similar developing of collaborative learning skills.

\subsection{Data Collection and Analysis}

Checklist of collaborative learning skills Scale is the instrument that helps assess both learners' developing of collaborative learning, as we mentioned earlier. The Checklist contains of 44 statements, and applied it on participants of the two groups, after using the communication tools (synchronous and asynchronous) to do their online group activities at the end of the studying the course. the items ranking was from 1 to 7 . (1) for strongly disagree and (7) for strongly agree. The total scores ranged from 0 to 308. We conducted Mann-Whitney U Test to determine whether or not there was a significant difference between collaborative learning skills of the two groups.

\section{Results}

To answer the research question: What is the difference between the effect of using synchronous and asynchronous communication tools in online group activities to develop collaborative learning skills?

We conducted an independent samples Mann-Whitney U Test to compare the degrees of collaborative learning skills checklist of the first group that used asynchronous communication tools with the degrees of collaborative learning skills checklist of the second group that used synchronous communications tools .Table 1 summarizes general descriptive statistics. The data in Table 1 indicate a significant difference between the first group that used asynchronous communication tools and second group that used synchronous communication tools. Asynchronous group score Asynchronous group score $Z=4.55$. A significant difference was found between asynchronous group grades and synchronous grades for the group that used asynchronous communication tools. The results suggest that developing collaborative learning skills was stronger in the group that used asynchronous communication tools than the group that used synchronous communication tools in online group activities.

Table 1. Descriptive statistics for the independent samples Mann-Whitney $\mathrm{U}$ Test analysis

\begin{tabular}{|c|c|c|c|c|c|c|}
\hline groups & $\mathrm{N}$ & $\begin{array}{c}\text { Mean } \\
\text { Rank }\end{array}$ & $\begin{array}{c}\text { Sum of } \\
\text { Ranks }\end{array}$ & $(\mathrm{U})$ & $(\mathrm{Z})$ & sig \\
\hline $\begin{array}{c}\text { Group (1) } \\
\text { Asynchronous } \\
\text { group }\end{array}$ & 18 & 24.83 & 447 & 12 & 4.55 & 0.05 \\
\hline $\begin{array}{c}\text { Group (2) } \\
\text { synchronous } \\
\text { group }\end{array}$ & 16 & 9.25 & 148 & & \\
\hline
\end{tabular}

\section{Discussion}

The primary aim of this study was to investigate the difference between the effect of using synchronous and asynchronous communication tools in online group activities to develop collaborative learning skills. The literature-review section suggests that, using electronic communication tools (synchronous and asynchronous) develop collaborative learning skills. However, there is a lack of studies that suggested which type of communication tools is effective in online group activities to develop collaborative skills. Therefore our research work addressed this point. This study's collection and analysis of the data yield answers the research question." What is the difference between the effect of using synchronous and asynchronous communication tools in online group activities to develop collaborative learning skills?" The Mann-Whitney U Test in table (1) indicates that using electronic communication tools develop collaborative skills. However, asynchronous communication tools had a stronger effect on developing collaborative learning skills than synchronous communication tool. The use of synchronous communication tool (skype) in online group activities did not develop collaborative learning skills similar to asynchronous communication tool (wiki) that of Using synchronous communication tool (skype) enabled the learners to accomplish tasks and participate in online group activities almost immediately This immediacy gave learners the impression, also, that they were attending a class similar to a regular class. However, during the first few sessions of the course when learners participated in their online group activities to discussed with each other the importance of multimedia-program production, the instructional design process, and evaluations of one another production of learning objects, there is a big chaos during their chatting with each other although not all students could participate in the same time. Moreover there is less time to think about what they want to say or their response to another; time may 
be a limiting factor. In addition, communication was so difficult because of the speed of data transaction with slower connections, Lack of reflection between collaborators If technology fails the collaboration session not possible, large time commitment for collaborators. Finally, lack documentation.

On the other hand, using asynchronous communication tool (wiki) in their online group activity was more appropriate to develop their collaborative learning skills. Participants could work with each other in more organized way. Participants of the group activities could to add, modify and post They could see and make changes to the document of the activity in real-time in a web browser, the ability to comment either on the document as a whole or on specific passages facilitate collaboration. Discussions and comments could be marked "resolved" to indicate group consensus. Asynchronous tool (wiki) possessed the advantage of being able to involve people from multiple time zones. In contrast of synchronous tool (skype), more time was allowed for responses which often-times results in enriched critical thinking and quality responses. Content can be accessed at any time within the context that comfortably suits them. In addition, asynchronous was helpful in capturing the history of the interactions of a group, allowing for collective knowledge to be more easily shared and distributed. In Conclusion, asynchronous tool was ideal for most collaborative writing and editing group activities.
(Christopher Machielse, 2011). It promoted group work, peer editing skills and multiple revisions.

\section{Conclusions}

Because collaborative learning skills is seen as an important crux to learning where participants interact with each other and exchange ideas and share information with each other, it is important to develop these skills. Using electronic communication tools is a useful practice for the development of higher order thinking skills, learner centered pedagogy, active and authentic learning, associative thinking, and collaborative learning skills. As result, two types of electronic communication tools (synchronous and asynchronous) used in this study to facilitate communication among students and develop collaborative learning skills. However, this study found that using asynchronous communication tools is more appropriate to develop collaborative learning skills than synchronous communication tools. Asynchronous communication tools were ideal for participants to work and cooperate with each other. Finally, the study support using synchronous communication tools in online group activities to develop collaborative skills. 


\section{Appendix A}

\section{Collaborative Learning Skills Checklist}

Instruction: In this survey, you will find a number of statements asking you about your learning experience during online group activity. Read each statement and indicate how you think or feel about the group activity. There are no right or wrong answers. Please give the answer that best describes how you think or feel. Your answers are completely confidential. It should take approximately 10-15 minutes to complete this survey.

1. Please check the tool your team use to communicate and interacted during the group project.

$\square$ Video call (Skype).

$\square$ Wiki.

To what extent do you agree with the following statements:

\begin{tabular}{|c|c|c|c|c|c|c|}
\hline 1 & 2 & 3 & 4 & 5 & 6 & 7 \\
\hline Strongly Disagree & Disagree & Slightly Disagree & Neutral & Slightly Agree & Agree & Strongly Agree \\
\hline
\end{tabular}

\begin{tabular}{|c|c|c|c|c|c|c|c|c|}
\hline No & Statement & 1 & 2 & 3 & 4 & 5 & 6 & 7 \\
\hline & I felt connected to my group members in this group activity. & & & & & & & \\
\hline & My interactions with my group members were sociable and friendly. & & & & & & & \\
\hline & My online interactions with my group members seemed personal. & & & & & & & \\
\hline & $\begin{array}{l}\text { In my interactions with my group members I was able to be myself and } \\
\text { showed what kind of teammate I really was. }\end{array}$ & & & & & & & \\
\hline & I felt like I was a member of a group in the group activity. & & & & & & & \\
\hline & I felt comfortable expressing my feelings to my group members. & & & & & & & \\
\hline & $\begin{array}{l}\text { I help others to find compromises between differing } \\
\text { Viewpoint. }\end{array}$ & & & & & & & \\
\hline & I introduce new ideas to groups in which I work. & & & & & & & \\
\hline & $\begin{array}{l}\text { When I logged on I was usually interested in seeing what my group } \\
\text { members were doing or had done. }\end{array}$ & & & & & & & \\
\hline & I build on the ideas of others. & & & & & & & \\
\hline & I suggest new ways of looking at problems. & & & & & & & \\
\hline & I suggest new ways of doing things. & & & & & & & \\
\hline & I trusted my group members in this group activity to help me if I needed & & & & & & & \\
\hline & I support and praise other team members & & & & & & & \\
\hline & $\begin{array}{l}\text { The actions of my group members in the group activity were easily visible } \\
\text { in our online system. }\end{array}$ & & & & & & & \\
\hline & I elaborate on what others have said. & & & & & & & \\
\hline & I am willing to compromise my own view to obtain a group consensus. & & & & & & & \\
\hline & When I saw that my group members were confused I offered help & & & & & & & \\
\hline & I use humour to remove stresses in groups in which I work. & & & & & & & \\
\hline & I clarify other peoples contributions. & & & & & & & \\
\hline & I try hard to keep up the group's energy level. & & & & & & & \\
\hline & I try to keep relations between group members harmonious. & & & & & & & \\
\hline & I ask others to take responsibility for particular tasks & & & & & & & \\
\hline & I usually lead and co-ordinate the team effort. & & & & & & & \\
\hline & $\begin{array}{l}\text { I listen carefully to what the other team members have to say and try to get } \\
\text { quiet group members to contribute. }\end{array}$ & & & & & & & \\
\hline & My interactions with the instructor were sociable and friendly & & & & & & & \\
\hline & I felt comfortable expressing my feelings to the instructor. & & & & & & & \\
\hline & My online interactions with the instructor seemed personal & & & & & & & \\
\hline & $\begin{array}{l}\text { The actions of the instructor in the group activity were easily visible in } \\
\text { our online system. }\end{array}$ & & & & & & & \\
\hline
\end{tabular}




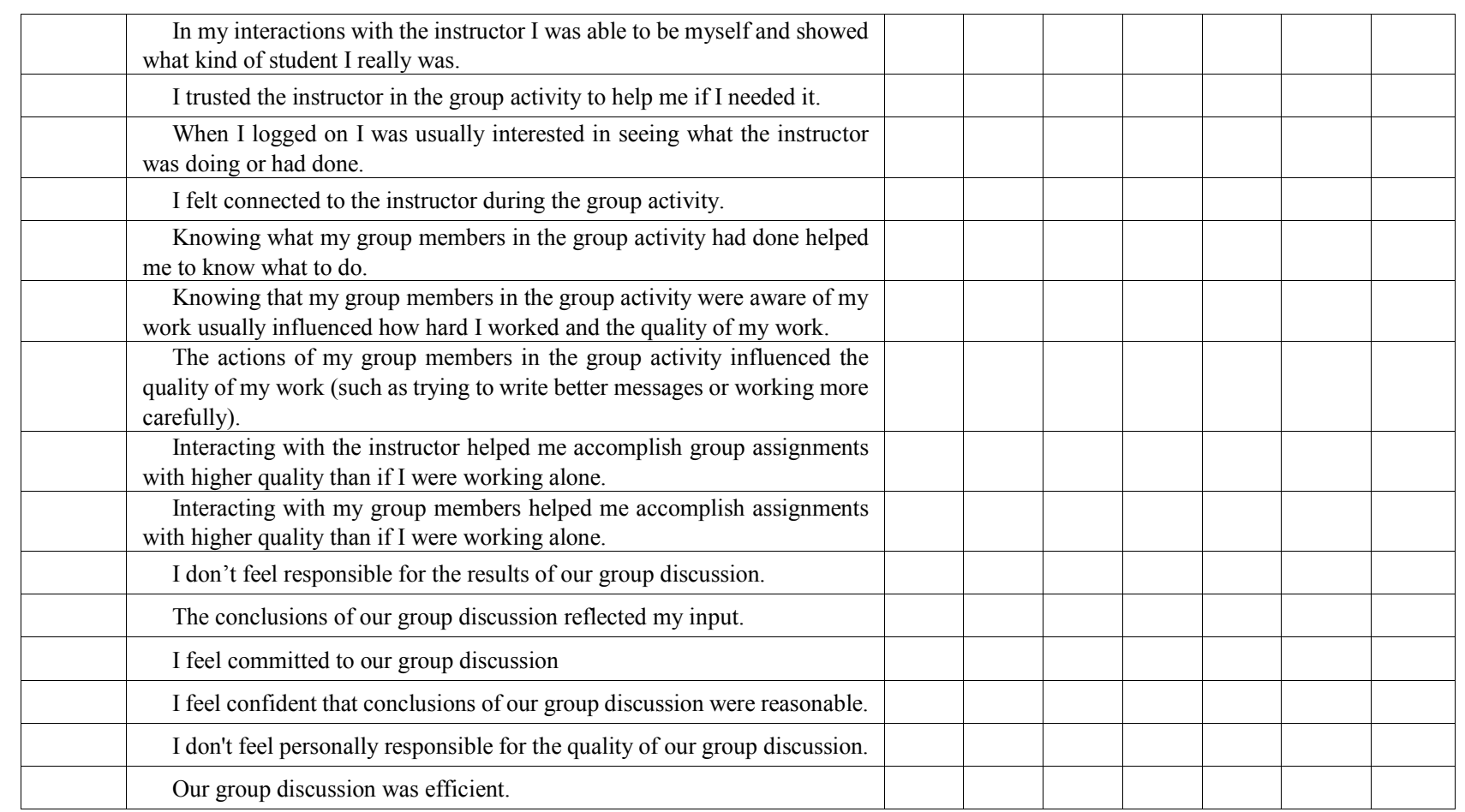

\section{REFERENCES}

[1] Mandernach. (2010). Online group work: making it meaningful and manageable, magna online seminars, Online University Education, Retrieved on $7^{\text {th }}$ June, 2013, available at

http://www.magnapubs.com/catalog/online-group-work-mak ing-it-meaningful-and-manageable/

[2] Farmer, B. Yue, A. and Brooks, C. (2008). Using blogging for higher order learning in large-cohort university teaching: A case study. Australian Journal of Educational Technology, 24(2), 123-136.

[3] Tekinarslan, E. (2008). Blogs: A qualitative investigation into an instructor and undergraduate students' experiences. Australasian Journal of Educational Technology, 24(4), 402-412.

[4] O’Donnell, M. (2006). Blogging as pedagogic practice: Artifact and ecology, Asia Pacific Media Educator,1, 17, 5-19.

[5] Schaffert, Sandra \& Ebner, Martin (2010). New Forms of and Tools for Cooperative Learning with Social Software in Higher Education. In: Brayden A. Morris \& George M. Ferguson (Ed.), Computer-Assisted Teaching: New Developments. Nova Science Pub, p. 151-165.

[6] Ebner, M. (2008). Will E-Learning Die, E-Learning: 21st Century Issues and Challenges, Audrey R. Lipshitz and Steven P. Parsons (Ed.), Nova Publishers, pp. 69-82, ISBN: 978-1-60456-156-2.

[7] Wang, S. K (2008). The Effects of a Synchronous Communication Tool (Yahoo Messenger) on Online, Learners' Sense of Community and their Multimedia
Authoring Skills ,New York Institute of Technology, New York , Journal of Interactive Online Learning , www.ncolr.org/jiol, Volume 7, Number 1, Spring 2008 , ISSN: 1541-4914.

[8] Ellis, J. \& Romano, D. (2008). Synchronous and asynchronous online delivery: How much interaction in e-learning is enough in higher education?. In G. Richards (Ed.), Proceedings of World Conference on E-Learning in Corporate, Government, Healthcare, and Higher Education 2008, 2615-2620.

[9] Gulati, S. (2008). Technology-Enhanced Learning in Developing Nations - a review. International Review of Research in Open Distance Learning 9-1 February

[10] Westbrook, C .(2012 ), Online Collaborative Learning in Health Care Education, European Journal of Open, Distance and E-Learning, 2012(2)

[11] Jeffries, P.R. (2006). Developing e-learning materials in E-learning in Nursing edited by Glen, S., and Moules, P., Palgrave Macmillan

[12] Gokhale, A. (1995). Collaborative Learning Enhances Critical Thinking, Journal of Technology Education 7 -1, Fall 1995.

[13] Anuratha, K. (2009). Collaborative skills and learning processes in a virtual context. Unpublished Master's Thesis, Universiti Kebangsaan Malaysia.

[14] Slavin, R. E. (1995). Cooperative Learning: Theory, Research and Practice. (2nd ed.), Boston: Allyn and Bacon.

[15] Springer L., Stanne, M. E., \& Donovan, S. S. (1999). Effects of small-group learning on undergraduates in science, mathematics, engineering, and technology: A meta-analysis. Review of Educational Research, 69, 21-51. 
[16] Johnson, D. W., Johnson, R. T., \& Smith, K. A. (1998) Cooperation learning returns to college. Change, 30(4), 26-36.

[17] Assiter, A. (Ed.). (1995). Transferable skills: A response to the skeptics. Transferable skills in higher education. London: Kogan Page.

[18] McGrath, K. (2000, September 4). Go team: How to determine if a project calls for a group effort or if it's better suited for one person. Network World, 61.

[19] Rovai, A. P., \& Barnum, K. T. (2002). On-line course effectiveness: An analysis of student interactions and perceptions of learning. Journal of Distance Education, 18(1), $57-73$.

[20] Kadriye, O. \& Lewis, D. (2006). Evaluating Of Online Group Activities Intra- Group Member Peer Evaluation, 22nd Annual conference on distance teaching and learning, Retrieved on 24th Aug, 2013 from, www.uwex.edu/disted/co nference/Resource_library/.../06_4136.pdf

[21] O'Reilly, T, (2005). What is Web 2.0? Design patterns and business models for the next generation software. Retrieved on $12^{\text {th }}$ August, 2013 from http://oreilly.com/web2/archive/ what-is-web-20.html

[22] Achterman, D. (2006). Making connections with blogs and wikis. California School Library Association Journal, 30, 1, 29-31.

[23] Godwin-Jones, R. (2003). Emerging technologies. Blogs and wikis: Environments for on-line collaboration. Language Learning \& Technology, 7, 2, 12-16.

[24] Ray, J. (2006) 'Blogosphere: The Educational Use of Blogs (aka Edublogs)' Kappa Delta Pi Record, 42, 4, 175-177.
[25] Weshah, H. (2012) Understanding the Pedagogies of Blogs, Wikis and Discussion Boards, International Journal of Instructional Technology and Distance Learning,. 9. (6), 59-77.

[26] Schwier, R. A., \& Balbar, S. (2002). The interplay of content and community in synchronous and asynchronous communication: Virtual communication in a graduate seminar. Canadian Journal of Learning and Technology, 28(2).

[27] Vonderwell, S., Liang, X.; \& Alderman, K. (2007) Asynchronous discussions and assessment in online learning. Journal of Research on Technology in Education, 39(3), 309-328.

[28] Park, Y. \& Bunk, C. (2007). Synchronous learning experiences: Distance and residential learners' perspectives in a blended graduate course. Journal of Interactive Online Learning, 6(4), 245-255.

[29] Pullen, M. J., and Snow, C. (2007) Integrating synchronous and asynchronous internet distributed education for maximum effectiveness. Education and Information Technologies, 12 (3). Retrieved August 22, 2013 from: http://www.springerlink.com/content/t413341p81444542/full text.pdf

[30] Branon, R. F., \& Essex, C. (2001). Synchronous and asynchronous communication tools in distance education: A survey of instructors. TechTrends, 45(1), 36-42.

[31] DiPetta, T. (1998). Community on-line: New professional environments for higher education. New Directions for Teaching and Learning, 76, 53-66.

[32] Matthews, R. (2002). Collaborative learning: Creating knowledge with students. In R.Menges and M. Weimer (Eds.), Teaching on Solid Ground. San Francisco, CA: Jossey-Bass. 